\title{
A Magnetically Coupled Multi-port, Multi-operation-mode Micro-grid With a Predictive Dynamic Programming-Based Energy Management for Residential Applications
}

\author{
Mohammad Jafari *, Zahra Malekjamshidi, and Jianguo Zhu \\ School of Electrical and Data Engineering, Faculty of Engineering and IT, University of Technology Sydney, \\ 15 Broadway, NSW 2007, Australia \\ *Corresponding Author, Email: Mohammad.jafari@uts.edu.au
}

\begin{abstract}
This paper presents the development of a residential micro-grid topology based on a combination of common magnetic and electrical buses. The magnetic bus interfaces two low voltage dc buses linking a PV and a fuel cell to a high voltage dc bus connected to a grid-tied single-phase bidirectional inverter. A battery is used to store the surplus energy of the system and stabilise the dc voltage of the fuel cell bus. A synchronised bus voltage balance (SBVB) technique is used to reduce the conduction losses and increase the soft switching operation range of the converters. To improve the maximum power point tracking (MPPT) performance and system efficiency, appropriate control techniques and compensation blocks are designed. The proposed micro-grid is able to operate in multiple grid-connected and off-grid operation modes according to a predictive 2D dynamic programming-based energy management. A mode selection and transition strategy is developed to select the appropriate operation mode and smooth the mode transition. A detailed study of the micro-grid including steady-state operation, small signal modelling, controller design, and energy management is presented. A prototype of the system is developed, and experimental tests are conducted for an energy management scenario.
\end{abstract}

Keywords: Dc-dc converter, energy management, micro-grid, optimisation, residential.

\section{Introduction}

Over the past century, the average global air temperature at the earth surface has been raised to about $0.74{ }^{\circ} \mathrm{C}$, which has generated serious concerns about the global warming and consequent environmental problems [1]. Some studies suggested that this is mainly caused by the excessive use of various fossil fuels, such as oil and coal. Therefore, the demand for environment-friendly sustainable energy sources has increased significantly over the past decades. The electricity generation as one of the major contributors to the environmental pollution is undergoing a fundamental change towards clean energy sources. In the residential sector, one of the major electricity users, renewable energy systems, such as solar, wind, and microcombined heat and power ( $\mu \mathrm{CHP})$, are growing rapidly. In Australia, the share of renewable energies in electricity in 2014 was $13.47 \%$, which is enough for supplying approximately 4.5 million average households [2]. The annual installed capacity of solar photovoltaic (PV) in the residential and commercial sectors has increased from 20 MW in 2008 to $1000 \mathrm{MW}$ in 2015 [2]. This can effectively reduce the electricity bill of the households and contributes significantly towards the reduction of greenhouse gas emission. Residential micro-grids as a solution for integration of small-scale renewable sources into the grid have been attractive for research over the last decade. Hybrid renewable energy systems are considered as a solution to overcome the intermittency of renewable resources, and many multi-port converter topologies are proposed for energy integration [3]. However, most of these topologies cannot be used in residential applications due to the lack of required standards and safety features, poor flexibility and control, and limited range of processing power. In Australia, the provisions for the demand response and power quality modes are recently included in the Australian/New Zealand standard for grid-connected renewable energy systems (AS/NZS 4777) [4]. The multiple mode operation converters with configurable settings and energy management using PC and Ethernet are recommended [4], [5] and currently are under development by some companies [6]. Therefore, there is a strong demand for more efficient, flexible, reliable and technically compatible topologies for residential micro-grids.

Research on the energy management of residential micro-grids mainly focused on the topologies, objectives, and methods. The majority of works are related to the demand-side management [7], [8], off-line optimization methods [9], [10] and online ruled-base power flow control techniques [11], [12]. Other methods using fuzzy controllers and neural networks also have been reported [13], [14]. Zhi et al. presented three control strategies for home energy management system namely, mixed integer programming (MILP), MILP with continuous relaxation and fuzzy logic controller and compared the results [15]. Among the optimization methods, dynamic programming attracted more interest as it can solve the problems with any type of constraints (linear or nonlinear, convex or concave, etc.)[9]. Nevertheless, none of the presented methods provides a device level study of the micro-grid topology and converters and their effects on the optimal energy management as provided in this paper. From a topological point of view, the proposed micro-grids are mainly based on a common $\mathrm{dc}$ or ac bus and multi-conversion configuration [13], [16]. In contrast to the common ac bus, the dc bus is simple and more efficient and no frequency and phase control is required although it does not provide the isolation requirement in residential applications [17], [18]. On the other hand, it cannot handle a wide variety of source voltages [3]. 

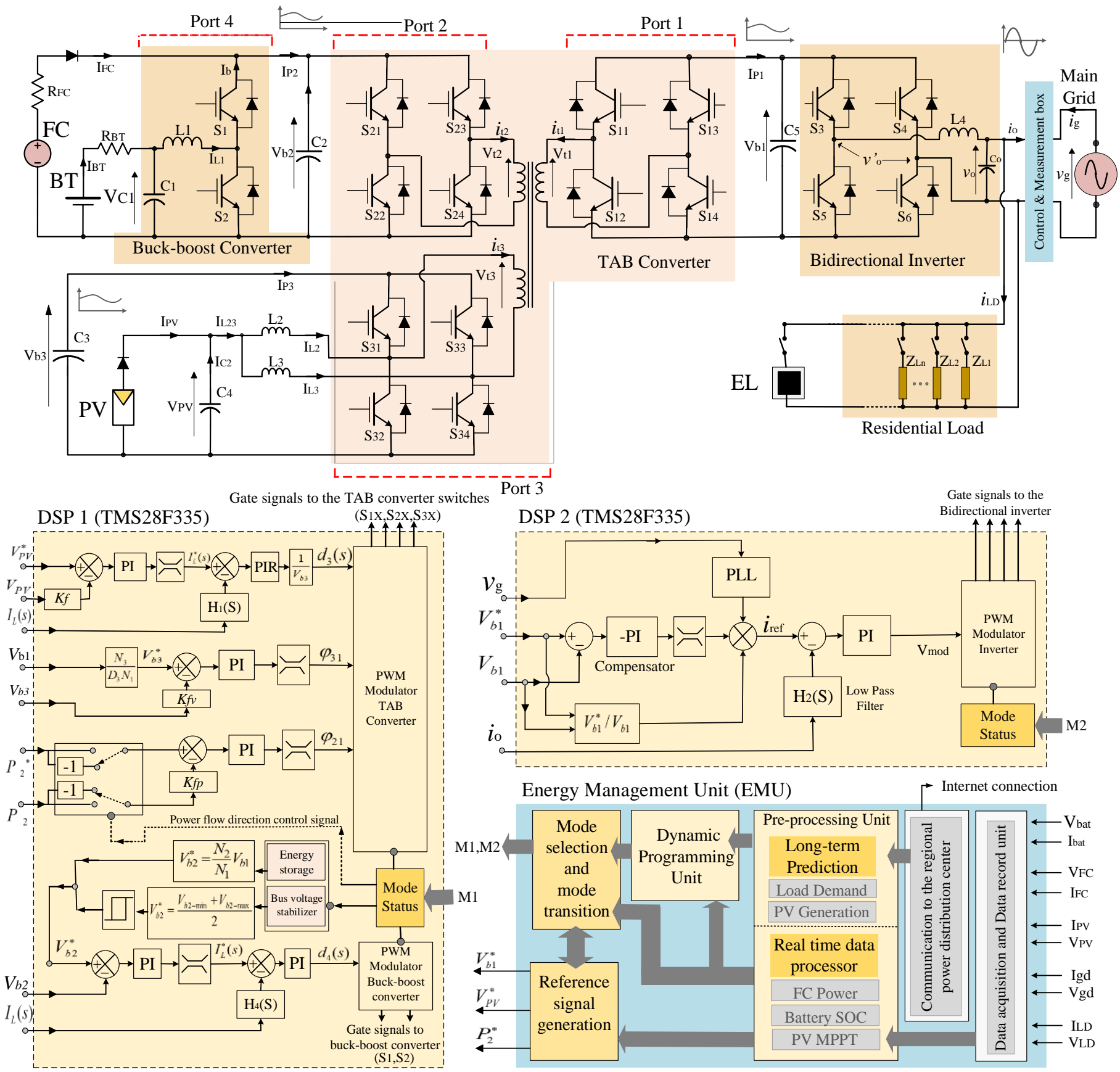

Fig.1 Schematic of the proposed micro-grid and control strategy

The third option in small-scale applications is using a common magnetic bus (multi-winding high-frequency transformer) which integrates the energies in the form of magnetic flux [19], [20]. In contrast to the multi-conversion based topologies, employing the magnetic link can reduce the number of voltage conversion blocks and control complexity [3], [21]. Consequently, the system efficiency can be increased, and the system complexity, size, and cost reduced [19], [20]. Despite the advantages of the magnetic links, their design and development become highly complex with the increasing number of windings and conversion ports [3], [20].Therefore, a combination of dc bus and the magnetic link is preferred in this research to utilize their advantages. In the proposed topology, low voltage sources such as PV, fuel cell and the batteries are linked to the common dc buses according to their voltage level and application. The dc buses are further linked to the highfrequency magnetic link through dc-ac converters.

To control the amount and direction of power flow between the ports through the magnetic link, a phase shift control technique is preferred due to its simplicity [19]-[22]. To link the low voltage sources such as PV, fuel cell and batteries to the common dc bus, boost or buck-boost converters are the most promising topologies [23]-[25].

In this paper, a micro-grid topology using a highfrequency magnetic link is introduced for residential microgrid applications. The topology of the proposed micro-grid and the control circuits are presented in Fig.1. The microgrid is designed to supply a $4 \mathrm{~kW}$ residential load from combined energy sources of a PV array, a fuel cell stack, and a battery bank. The fuel cell stack is used as the backup energy source while the PV is considered as the preferred source to supply the load and possibly the grid. The battery 
is used as the energy storage device and also balances the voltage of the dc bus due to the slow dynamic response of the fuel cell. It also handles the quick start up which lets the fuel cell warm up. An electrolyser is considered as an optional load to generate the required hydrogen for the fuel cell and increase the systems flexibility and energy storage capability.

As shown in the figure, the micro-grid structure includes a triple active bridge (TAB) dc-dc converter which couples ports one, two, and three. Port one is a bidirectional port that transfers the power from the renewable sources or battery to the high voltage dc bus and further to the inverter, local loads and grid. The single-phase inverter links the proposed micro-gird to the main grid. It also operates in the rectifier mode to transfer the power reversely from the grid to the battery (using Ports two and four simultaneously) and stabilize the high voltage dc bus. The interleaved boost converter is used in Port three to step up the PV output voltage and utilize the maximum power point tracking (MPPT). The interleaved inductors reduce the current ripple and improve the MPPT performance and the PV panel efficiency. On the other hand, a bi-directional buck-boost dc-dc converter is used in Port four to control the charge and discharge of the battery.

In summary, as the main contribution, this paper aims to present design, control and energy management of a microgrid topology based on the most recent standards of the residential renewable energy systems (AS/NZS 4777, IEEE 1547 and IEC 62109). Therefore, several control techniques and hardware features have been used to improve the system performance according to the required standards which make it distinct from previously reported systems. The applied improvements include:

-Using a magnetic link to interface the micro-grid components which isolates the converter ports for safety requirements, increases the micro-grid flexibility and operation modes and reduces the control complexity.

- Using interleaved topology in the PV port which improves the maximum power point tracking (MPPT) performance by reducing the high-frequency current ripples and results in more stable MPPT, smaller size filter components, and wide input voltage range.

- Using a synchronized bus-voltage balance (SBVB) technique to reduce the root mean square (RMS) and the peak value of the currents in the windings of the magnetic link and switching devices which reduce the conduction loss. This also leads to an equal volt-seconds product on the windings which increase the soft switching operation range of the converters.

- Using a compensation block in the inverter control loop to reduce the low-frequency current ripple propagated from the inverter output and the ac bus to the high-voltage dc bus and further to the PV and fuel cell buses. This can yield higher performance MPPT and smaller size filter components.

-The proposed micro-grid can operate in a large number of grid-connected and off-grid operation modes and different energy management scenarios compared to the previously reported systems.

-A novel energy management based on the real-time data and long-term predictions of the PV generation and load demand using a 2D dynamic programming is proposed. The efficiency performance of the micro-grid components such as converters, transformer and battery loss is included in the optimization algorithm.

-A mode transition strategy by defining a state transition diagram (STD) and bridging modes is employed to smooth the mode transition.

The performance of the proposed topology and the control technique is experimentally validated for an energy management scenario through energy distribution and cost analysis. As this paper is going to analyse both device level and system level control of the micro-grid, some details are ignored due to the page length limit.

The rest of the paper is organized as follows. The microgrid steady-state operation is studied in section 2 . In section 3 , the controller design techniques and section 4 , operation modes and energy management method of the proposed micro-grid are reviewed. The experimental test results are presented in Section 5 and conclusions in section 6.

\section{Steady State Operation of the Micro-grid}

The $\mathrm{TAB}$ converter is used to transfer the power between port one, two and three by introducing leading or lagging phase shifts between the high-frequency square waves (generated by H-bridge converters) applied to the windings of the magnetic link [19]-[22]. The high-voltage dc of bus one $\left(V_{b 1}\right)$, should be kept constant during the normal operation of the converter since a regulated voltage is required to supply the inverter and consequently output loads. The power transfer between ports two and one in the proposed TAB converter considering constant duty cycle at Port one and two $\left(D_{1}=D_{2}=1\right)$, can be found from [19] as

$$
P_{21}=\frac{V_{b 2} V_{b 1}}{2 n_{21} \pi f L_{21}} \varphi_{21}\left(1-\frac{\left|\varphi_{21}\right|}{\pi}\right)
$$

where $\varphi_{21}$ is the leading phase shift of voltage of port two $\left(v_{\mathrm{t} 2}\right)$ to voltage of port one $\left(v_{\mathrm{t} 1}\right), V_{b 1}$ and $V_{b 2}$ voltages of bus one and two respectively, $L_{21}$ the summation of the leakage inductance of winding one and leakage inductance of winding two referred to winding one, $f$ the switching frequency and $n_{21}$ turns ratio of winding two to one.

The power transferred from port three to port one, $P_{31}$, can be calculated by

$$
\begin{gathered}
\text { Mode I: } P_{31}=\frac{V_{b 3} V_{b 1}}{2 \pi f n_{31} L_{31}}\left[\begin{array}{l}
\varphi_{31}\left(1-\frac{\left|\varphi_{31}\right|}{\pi}\right)- \\
\operatorname{sign}\left(\varphi_{31}\right)\left[\frac{\pi}{4}\left(1-D_{3}\right)^{2}\right]
\end{array}\right] \text {, for }\left|\varphi_{31}\right|>\varphi_{B} \\
\text { Mode II : } P_{31}=\frac{V_{b 3} V_{b 1}}{2 \pi f n_{31} L_{31}} D_{3} \varphi_{31}, \text { for }\left|\varphi_{31}\right| \leq \varphi_{B}
\end{gathered}
$$

where $\varphi_{31}, V_{b 3}, V_{b 1}, L_{31}, n_{31}$, and $f$ are defined similarly to (1) respected to windings three and one. $D_{3}$ is the duty ratio of voltage on port three and $\varphi_{B}=\pi\left(1-D_{3}\right) / 2$ is a boundary angle depending on the range of phase shift between the waveforms of $v_{t 3}$ and $v_{t 1}$ [19]. As there are only two independent variables $\left(\varphi_{21}\right.$ and $\left.\varphi_{31}\right)$ to control the power flow, $\varphi_{32}$ is redundant and can be written based on phase angles $\varphi_{21}$ and $\varphi_{31}\left(\varphi_{32}=\varphi_{31}-\varphi_{21}\right)$. Therefore, the power flow between ports three and two $\left(P_{32}\right)$ can be defined as 


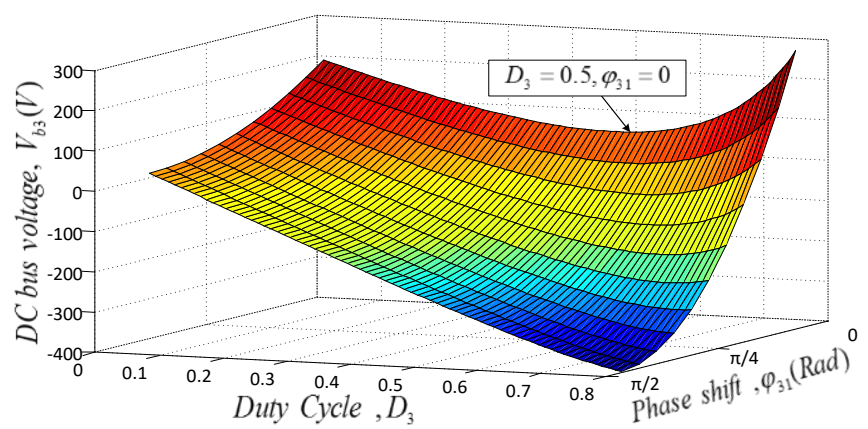

Fig.2. Variation of dc bus voltage on the PV port based on the duty cycle and phase shift angle

$$
\text { Mode } I: P_{32}=\frac{V_{b 3} V_{b 2}}{2 \pi f n_{32} L_{32}}\left[\begin{array}{l}
\left(\varphi_{31}-\varphi_{21}\right)\left(1-\frac{\left|\left(\varphi_{31}-\varphi_{21}\right)\right|}{\pi}\right) \\
-\operatorname{sign}\left(\varphi_{31}-\varphi_{21}\right)\left[\frac{\pi}{4}\left(1-D_{3}\right)^{2}\right]
\end{array}\right], \text { for }\left|\left(\varphi_{31}-\varphi_{21}\right)\right|>\varphi_{B}
$$$$
\text { Mode II : } P_{32}=\frac{V_{b 3} V_{b 2}}{2 \pi f n_{32} L_{32}} D_{3}\left(\varphi_{31}-\varphi_{21}\right), \text { for }\left|\left(\varphi_{31}-\varphi_{21}\right)\right| \leq \varphi_{B}
$$

where $\varphi_{B}$ and $n_{32}$ are defined similarly to (1).

In port two, the fuel cell operates as the primary source and the battery is used as bus voltage stabilizer. In the case that the battery is in the charging or discharging mode, the reference voltage of the dc bus $\left(V_{b 2}^{*}\right)$ is defined according to the SBVB rule considering high voltage dc bus $\left(V_{\mathrm{b} 1}\right)$ as reference by

$$
V_{b 2}^{*}=\frac{N_{2}}{N_{1}} V_{b 1}
$$

The bidirectional buck-boost converter presented as port four is used to transfer the power between the battery and the dc bus through a charging or discharging process. The converter operation during both charge and discharge modes is similar and the only difference is in the duty cycles of complementary drive signals applied to $S_{1}$ and $S_{2}$. Operation in the buck (charging) or the boost (discharging) mode is determined by the duty ratio of the driving signal applied to $\mathrm{S}_{2}\left(D_{4}\right)$ and a critical duty ratio $\left(\boldsymbol{D}_{4}^{*}\right)$. The critical duty ratio where the average of inductor current is equal to zero is defined using the dc bus voltage $\left(V_{\mathrm{b} 2}\right)$ and the battery voltage $\left(V_{\mathrm{BT}}\right)$ as

$$
D_{4}^{*}=1-\frac{V_{B T}}{V_{b 2}}
$$

The converter operates in the boost $\left(D>D_{4}^{*}\right)$, buck $\left(D<D_{4}^{*}\right)$ or in the boundary between buck and boost modes $\left(D=D_{4}^{*}\right)$. The average of the inductor current in the steady state is defined by

$$
I_{L 1}=\frac{D_{4} \cdot V_{b 2}-V_{B T}}{R_{B T}+r_{L 1}}
$$

where $R_{B T}$ and $r_{L 1}$ are the internal resistance of the battery and inductor $L_{l}$ respectively.

In the PV port, the interleaved converter boosts the output voltage of the PV to the desired range (100-110V). The complementary pattern of the currents in $L_{2}$ and $L_{3}$ reduces the generated high-frequency ripple on the PV output current and their duty cycle $\left(D_{3}^{\prime}\right)$ is used to adjust the operating point of the PV on maximum power point (MPP). Therefore, the duty cycle of the square wave on the transformer winding $\left(v_{\mathrm{t} 3}\right)$, presented as $D_{3}$ depends on the $D_{3}^{\prime}$ and its variation due to the MPPT requirement. The relation between $D_{3}$ and $D_{3}^{\prime}$ can be defined as

$$
D_{3}=\left\{\begin{array}{cc}
2 D_{3}^{\prime} & D_{3}^{\prime}<0.5 \\
2\left(1-D_{3}^{\prime}\right) & D_{3}^{\prime}>0.5
\end{array}\right.
$$

On the other hand, to maintain the SBVB technique and a full range of ZVS operation for all converter ports, the voltsecond product on all windings of the magnetic link should be kept equal [19], [22]. Therefore, the phase shift angle $\varphi_{31}$ is used as control variable to adjust the dc bus voltage of the $\mathrm{PV}$ port $\left(V_{b 3}\right)$ on the desired value $\left(V_{b 3}^{*}\right)$ which is defined by

$$
V_{b 3}^{*}=\frac{N_{3}}{D_{3} N_{1}} V_{b 1}
$$

Fig.2 shows the variation of dc bus voltage $\left(V_{\mathrm{b} 3}\right)$ as a function of $D_{3}$ and $\varphi_{31}$. For example, all points on the presented dashed line result in a zero voltage for dc bus $\left(V_{b 3}\right)$.

The soft switching condition for the TAB converter, bidirectional buck-boost converter and the interleaved converter as well known topologies has been studied in details in the literature [19],[26]-[28]. In the case of the $\mathrm{TAB}$ converter, the soft switching condition for a full range of operation of three conversion ports can be achieved as long as the volt-second product of the voltages applied to the corresponding windings of the magnetic link is kept equal from [26]:

$$
V_{b 1} D_{1}=V_{b 2}\left(\frac{N_{1}}{N_{2}}\right) D_{2}=V_{b 3}\left(\frac{N_{1}}{N_{3}}\right) D_{3}
$$

The amplitude of the current in the switching instants defines the ZVS condition for each H-bridge converter. Applying SBVB technique based on (9) results in a negative amplitude of currents $i_{t 1}, i_{t 2}$ and $i_{t 3}$ at the rising time of $v_{t 1}, v_{t 2}$ and $v_{t 3}$ respectively and a positive amplitude at their falling time. This approves that the anti-parallel diodes of each IGBT switch is in ON state at its switching instance and therefore, the ZVS condition is realised as presented in Fig.2 (a). In the case of the bidirectional buck-boost and interleaved converters, the ZVS condition is realised by applying complementary gate signal and limiting the inductances to less than a critical value [27]. This enforces the inductor current to changes between negative and positive values for entire operation range, and consequently, the ZVS condition for both switches is realised [27].

The high voltage dc on the inverter bus $\left(V_{b l}\right)$ is selected as a reference for other two ports. It is regulated by bidirectional inverter according to the reference value defined by EMU as will be discussed in section 3 .

\section{Design of the Device Level Controllers}

This section provides a study on the design of controllers for the converters in the proposed micro-grid.

The main control strategies in the proposed micro-grid are defined as follows.

-In port two, the amount and direction of power flow between port two and one $\left(P_{21}\right)$ are controlled by leading or lagging phase angle $v_{\mathrm{t} 2}$ to $v_{\mathrm{t} 1}\left(\varphi_{2 l}\right)$. The reference power to/from this port $\left(P_{2}^{*}\right)$, can take positive or negative values depending on the power flow direction. It is defined by EMU according to the required amount of power that needs to be supplied by either fuel cell or Battery (boost mode) or absorbed by the battery (buck mode). 


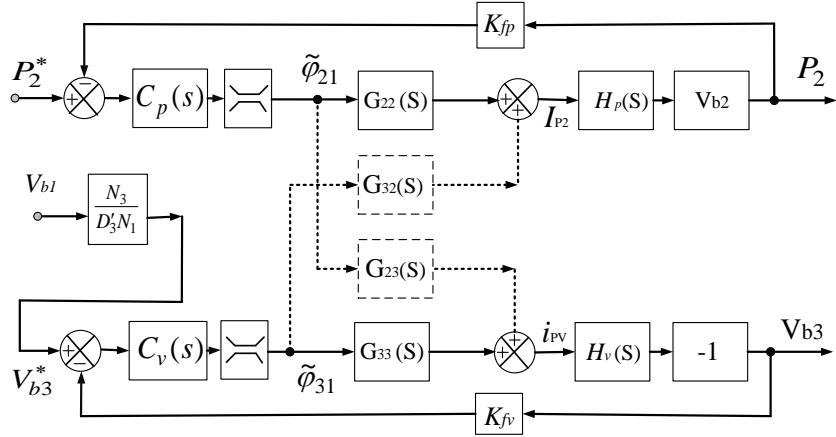

Fig.3. Block diagram of the TAB converter control system

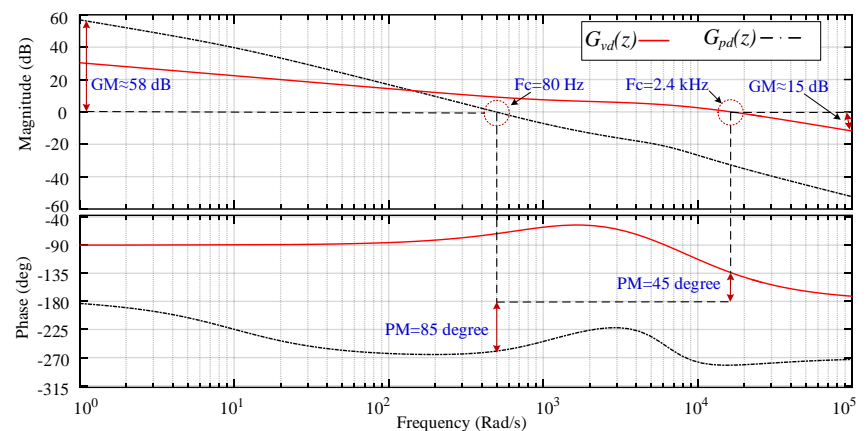

Fig.4. The amplitude and phase bode diagrams of the TAB converter control system

- In port three (PV port), the control objective is regulation of dc bus voltage $V_{\mathrm{b} 3}$ (voltage on capacitor $C_{3}$ ) by using phase shift angle between $v_{\mathrm{t} 3}$ and $v_{\mathrm{tl}}\left(\varphi_{31}\right)$. It also defines the amount of power flow from port three to one $\left(P_{31}\right)$. The reference voltage for this port $\left(V_{b 3}^{*}\right)$, is determined to maintain the SBVB technique using real-time values of $V_{\mathrm{b} 1}$ and $D_{3}$ from (8).

-In the port one, high voltage dc bus $\left(V_{\mathrm{b} 1}\right)$ is regulated by inverter/rectifier operation modes on a reference value $\left(V_{b 1}^{*}\right)$ defined by EMU.

-The interleaved boost converter regulates the PV voltage $\left(V_{\mathrm{PV}}\right)$ by changing ${ }_{D_{3}^{\prime}}$ to maintain the MPPT. The PV voltage and $\mathrm{dc}$ bus voltage regulation controllers operate almost independently due to the slower dynamic response of the MPPT control signal.

-In port four (battery port), the duty cycle $\left(D_{4}\right)$ is used to stabilize the dc bus voltage when the fuel cell is active and the battery is in standby. It also is used to manage the bidirectional power flow by controlling the battery charge and discharge currents. The dc bus reference voltage $\left(V_{b 2}^{*}\right)$ is defined according to the SBVB rule while a $5 \%$ hysteresis band is considered in the first case.

To design a control system for the proposed micro-grid, small signal models of the converters are required. This section provides a brief review on small signal modelling and controller design procedure of the converters.

The small signal model of the TAB converter is obtained by defining the average of dc current in each port $\left(I_{L D}, I_{F C}\right.$ and $\left.I_{P V}\right)$ as a function of phase shift angles $\left(\varphi_{2 I}\right.$ and $\left.\varphi_{3 I}\right)$ from [19],[22]

$$
I_{P 2}=\frac{P_{2}}{V_{b 2}}, I_{P 1}=\frac{P_{1}}{V_{b 1}}, I_{P 3}=\frac{P_{3}}{V_{b 3}}
$$

where $P_{1}=P_{31}+P_{21}, \quad P_{2}=P_{21}-P_{32}$, and $P_{3}=P_{31}+P_{32}$ can be calculated by (1) to (3). The current in port one $\left(I_{P I}\right)$, is redundant as there are only two independent variables. As can be seen in (2) and (3), the power flow and consequently the average currents of the ports are nonlinear functions of control variables, $\varphi_{21}, \varphi_{31}$ and $D_{3}$. Therefore, to design a linear control model, they need to be linearized around the operation point of the converter. As $D_{3}$ is varying according to the MPPT requirement, its dynamic variation is much slower compared to the phase shift angles and can be considered as a constant value for dynamic analysis. The linearized function of the currents $I_{P 2}$ and $I_{P 3}$ can be presented as

$$
\tilde{I}_{P 2}=G_{22} \tilde{\varphi}_{21}+G_{32} \tilde{\varphi}_{31}, \quad \tilde{I}_{P 3}=G_{23} \tilde{\varphi}_{21}+G_{33} \tilde{\varphi}_{31}
$$

where $G_{22}$ and $G_{33}$ are direct transfer functions and $G_{32}$ and $G_{23}$ the coupling transfer functions of the average currents to the phase shift angles and can be defined as

$$
\begin{aligned}
& G_{22}=\left.\frac{\partial I_{P 2}}{\partial \tilde{\varphi}_{21}}\right|_{\left(\varphi_{21}, \varphi_{31}, D_{3 *} *\right)} G_{32}=\left.\frac{\partial I_{P 2}}{\partial \tilde{\varphi}_{31}}\right|_{\left(\varphi_{210}, \varphi_{31}, D_{3 *}\right)} \\
& G_{23}=\left.\frac{\partial I_{P 3}}{\partial \tilde{\varphi}_{21}}\right|_{\left(\varphi_{21}: \varphi_{31}, D_{3 *}\right)} G_{33}=\left.\frac{\partial I_{P 3}}{\partial \widetilde{\varphi}_{31}}\right|_{\left(\varphi_{21}, \varphi_{31} *, D_{3 *}\right)}
\end{aligned}
$$

where $\varphi_{21 *}, \varphi_{31 *}$ and $\mathrm{D}_{3^{*}}$ are the phase shift angles and the duty ratio at the converter operating point. Fig.3 illustrates the block diagram of the TAB converter control system. All transfer functions in this paper are obtained by using the converter parameters presented in Table.2, Appendix-(A). The control blocks $K_{f P}$ and $K_{f v}$ are the feedback gains defined by the parameters of signal conditioning circuits and $H_{p}(\mathrm{~s})$ and $H_{v}(\mathrm{~s})$ are the low pass filter and output capacitor transfer functions respectively and are defined as

$$
H_{p}(s)=\frac{1}{1+\tau_{1} S}, H_{v}(s)=\frac{1}{C_{3} S}
$$

where $\tau_{l}=0.6 \mathrm{~ms}$ is the time constant of the filter. The time delay caused by computational functions and sample and holds have been considered in the controller design. $C_{P}(s)$ and $C_{v}(s)$ are the PI compensator transfer functions and are defined as

$$
C_{p}(s)=K_{P}+\frac{K_{I}}{S}
$$

The controller gains $\left(K_{P}\right.$ and $\left.K_{I}\right)$ are defined according to the required crossover frequency $\omega_{c}$ and phase margin $\varphi_{m}$ of the voltage and power open loop transfer functions [29],[30]. For particular values of crossover frequency, $\omega_{c}$, and phase margin, $\varphi_{m}$, the value of coefficients, $K_{v}$ and $K_{i}$ for PI compensators can be defined as

$$
K_{I}=\frac{\operatorname{Cos}(\theta)}{\left|G\left(j \omega_{c}\right)\right|}, K_{P}=\frac{-\omega_{c} \operatorname{Sin}(\theta)}{\left|G\left(j \omega_{c}\right)\right|}
$$

where

$$
\theta=180+\varphi_{m}-\angle G\left(j \omega_{c}\right)
$$

and $G(j \omega)$ is the open loop transfer function of the voltage or power control systems. The voltage regulation and power regulation compensators are defined as

$$
C_{p}(s)=0.895+\frac{1.56}{S}, C_{v}(s)=35+\frac{185}{S}
$$

Fig.4 shows the bode diagrams of the loop gains of the voltage and power regulations. To decouple the voltage and power control loops, the crossover frequency of voltage loop is selected about $2.4 \mathrm{kHz}$ and power loop is selected as 80 $\mathrm{Hz}$. On the other hand, the regulation of fuel cell power does not need to be as fast as voltage regulation on the PV port 


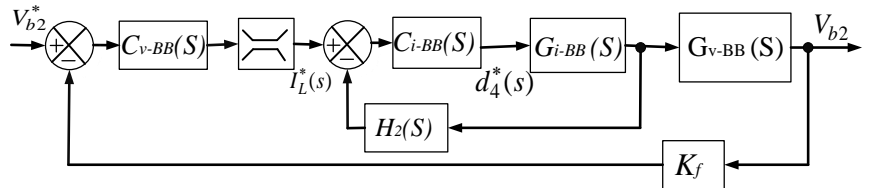

Fig.5. The control diagram of the bidirectional buck-boost

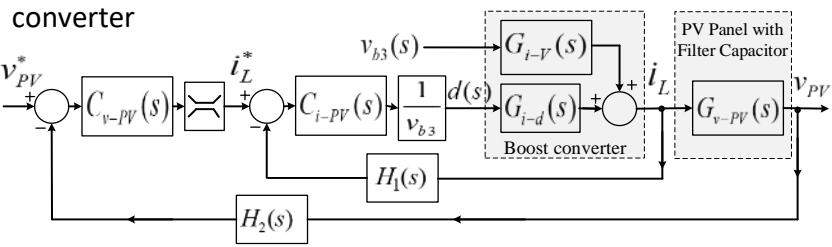

Fig.6. The control diagram of the interleaved boost converter

bus. Therefore, the power control loop has slower dynamic response compared to the voltage regulation loop. As can be seen for voltage control loop $\mathrm{GM}=30 \mathrm{db}$ and $\mathrm{PM}=45^{\circ}$ and for the power control loop $\mathrm{GM}=58 \mathrm{db}$ and $\mathrm{PM}=85^{\circ}$ which verifies the stability of the designed controller.

In the case of the bidirectional buck-boost converter, due to the reality that both operation modes of the buck-boost converter share the same power circuit, there is a possibility to design a single controller for both charge and discharge modes. The state space equations of the converter and the resultant transfer functions are presented in Appendix-(B). To design a control system for the bi-directional converter, a dual loop control system using proportional-integral (PI) controller is considered as presented in Fig.5. In this structure, the outer voltage loop provides a reference for the inner current loop. The $C_{v-B B}(s)$ and $C_{i-B B}(s)$ blocks are the continuous-time PI compensator of the voltage and current control loops respectively. The compensators are designed similar to (14)-(16) based on the crossover frequency and phase margin considering that the inner current loop should be designed for higher dynamic response compared to the outer voltage loop to avoid interaction between loop operations.

In the PV port, the H-bridge switches $S_{31}, S_{32}, S_{33}$, and $S_{34}$ have been shared in both interleaved boost and TAB dc-dc converters and $C_{3}$ is used as an energy buffer between the two conversion stages. Therefore, the PV port can be modelled as an interleaved boost converter cascaded by a voltage source dc-ac H-bridge converter. The output voltage from PV is adjusted on MPP by varying ${ }_{D_{3}^{\prime}}$ while the dc bus voltage, $V_{b 3}$, is controlled by the phase shift angle, $\varphi_{31}$. A variable step size incremental conductance MPPT method is used in this paper [31]. To design a robust MPPT, a dual loop control system including the inner current loop which controls the inductor current and outer voltage loop which controls the PV voltage is used as presented in Fig.6 [24].

The block diagrams $\mathrm{H}_{1}(\mathrm{~s})$ and $\mathrm{H}_{2}(\mathrm{~s})$ are the transfer functions of low-pass, first-order filters. The state averaged equations of the PV voltage control and inductor current control and the resultant transfer functions are presented in Appendix-(B). The compensator blocks of the inductor current control $C_{i-P V}(s)$ and $\mathrm{PV}$ voltage control $C_{v-P V}(s)$ are designed as

$$
C_{v-P V}(s)=0.153+\frac{14.56}{S}, C_{i-P V}(s)=1.2+\frac{0.0025}{S}+\frac{2 \omega S}{S^{2}+4 \pi S+(2 \omega)^{2}}
$$

As can be seen, a resonant component is added to the current control loop to increase the control gain at $\omega=100 \pi$

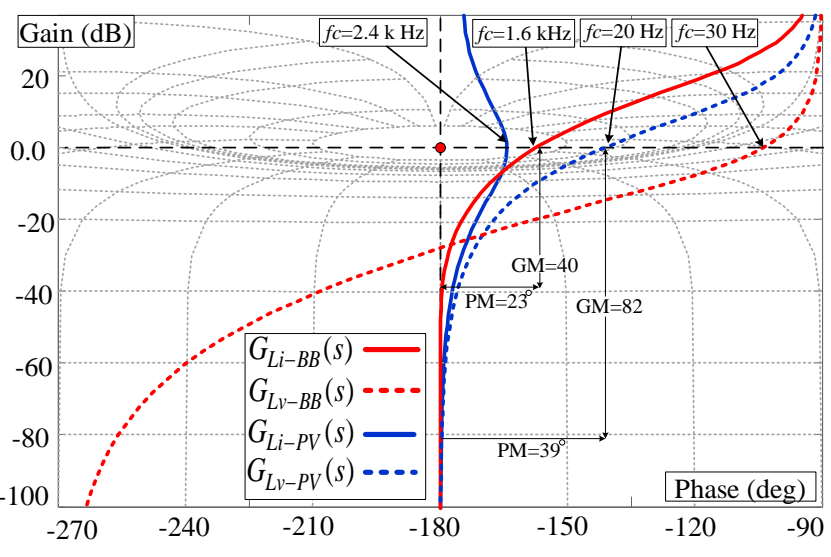

Fig.7. The Nichols chart of phase and gain variation of the current and voltage control loops in buck-boost bi-directional $\left(G_{L i-B B}(\mathrm{~s})\right.$, $\left.G_{L v-B B}(\mathrm{~s})\right)$ and interleaved boost converter $\left(G_{L i-P V}(\mathrm{~s}), G_{L v-P V}(\mathrm{~s})\right)$ respectively.

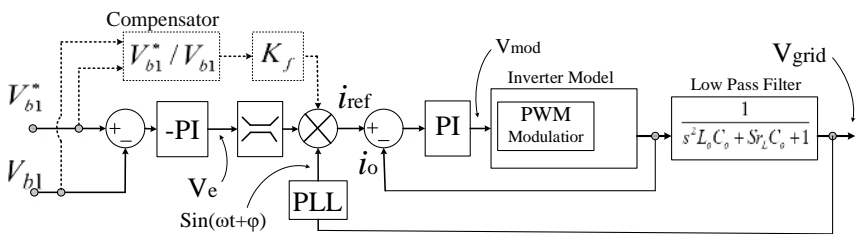

Fig.8. The control scheme of bi-directional single phase inverter

which reduces the low-frequency ripple propagated from high voltage bus and improves the MPPT performance considerably. To analyse the stability of the bi-directional buck-boost and interleaved boost converters, the open loop transfer functions of voltage and current controllers are presented in the Nichols chart in Fig.7. The crossover frequencies, gain margin and phase margins can be measured easily on the same graph.

In the bidirectional inverter, a double loop control strategy based on direct current-control technique is used to force the instantaneous output current of the inverter to follow the provided sinusoidal reference voltage. The referenced ac voltage is synchronized with the grid voltage in grid-connected condition by using a PLL block or generated independently in off-grid mode. The direct current control technique provides high power factor, low THD and fast dynamic response [32], [33]. The bidirectional power flow enables the inverter to operate in the rectifier mode and transfers energy from grid to the multi-port dc-dc converter and further to the battery. It also can be used to compensate for the voltage fluctuations of the high voltage dc-bus which improves the stability of $V_{b l}$ due to the SBVB requirement. This mode also is used at the start up time of the multi-port converter to reduce the inrush current and facilitate the soft start. The bidirectional power flow ability is achieved by adjusting the high voltage dc bus reference $\left(V_{b 1}^{*}\right)$. As can be seen in Fig.8, the dc voltage of the inverter bus, $V_{\mathrm{b} 1}$, is compared with a predefined reference voltage, $V_{b 1}^{*}$, and is forced to follow the reference with zero error by using the control loop. The amplitude and direction of power through the inverter is controlled by the output current. The direction of current and power flow is defined according to the value of $V_{\mathrm{e}}$ which is the output of the negative PI controller in the voltage control loop. In the case of $V_{b 1}>V_{b 1}^{*}, V_{\mathrm{e}}$ is positive and increasing which allows the converter to operate as an inverter and when $V_{b 1}<V_{b 1}^{*}, V_{\mathrm{e}}$, is negative and decreasing 


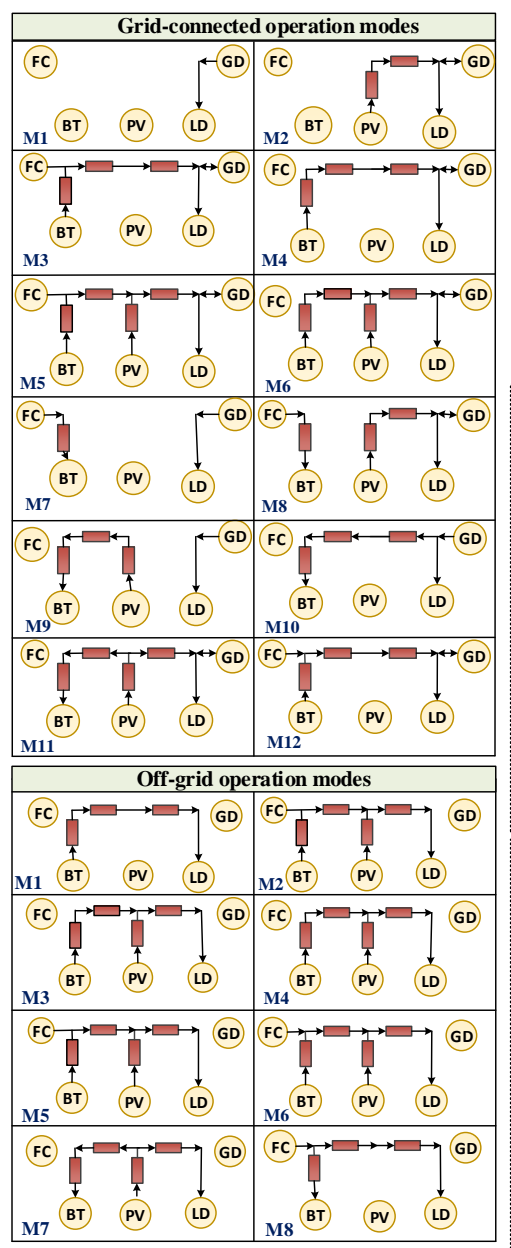

Fig.9. Operation modes of the proposed micro-grid in grid-connected and offgrid modes

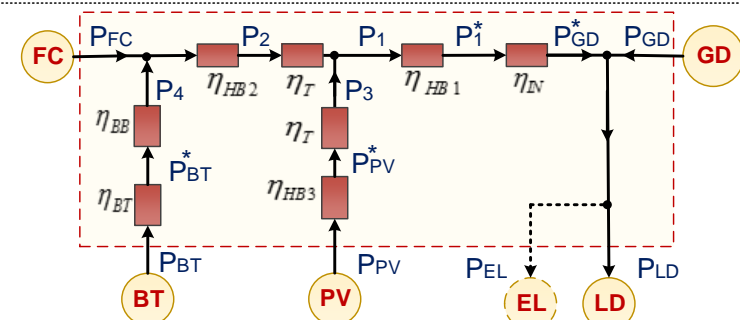

Fig.10. Power flow model of the proposed micro-grid
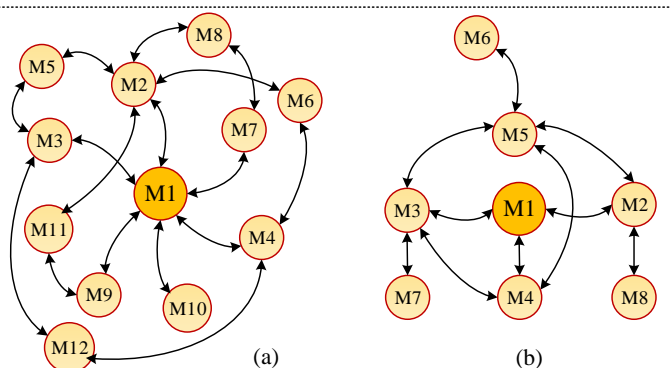

(b)

Fig.11. State transition diagram of The mode transition unit in (a) grid connected and (b) islanded operation modes

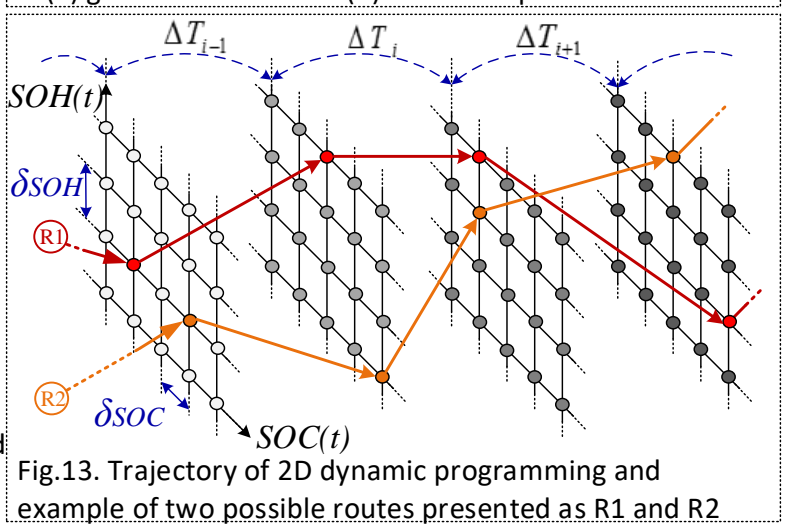

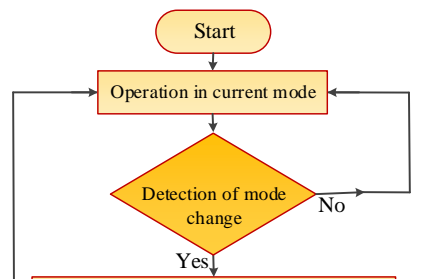

Checking the new mode primary condition
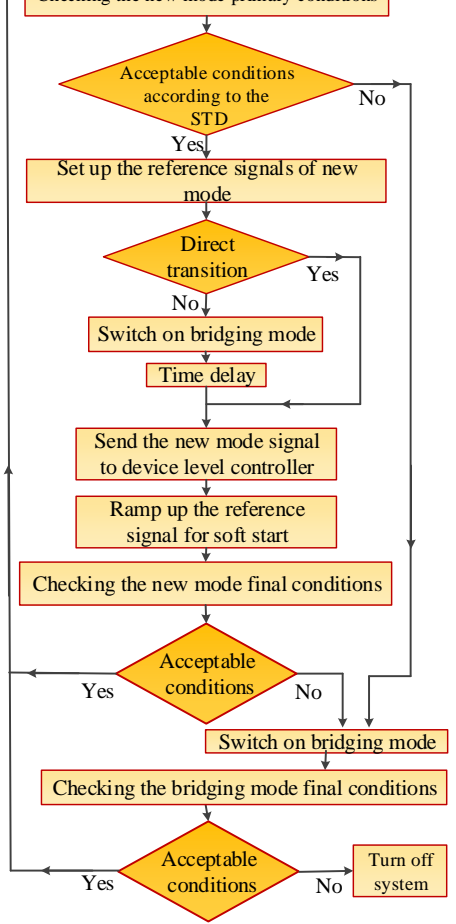

Fig.12. Flowchart of mode transition process and forces the converter to work as a PWM rectifier. The PI compensators are defined similarly based on the required crossing frequency and phase margins of the inverter current and voltage control loops.

A common problem in grid-tied inverters is the appearance of a voltage ripple with the frequency $2 \omega$ on the dc bus voltage. In this paper, a compensation block is added to the control loop as a feed-forward input. The compensation block which is equal to $V_{b 1}^{*} / V_{b 1}$, applies a reverse fluctuating signal with frequency $2 \omega$ to the inductor current to compensate the low-frequency ripple on the high voltage dc bus.

\section{Operation Modes and Energy Management}

The proposed micro-grid is able to operate in several grid-connected and off-grid modes depending on the power flow direction and active sources as presented in Fig.9. The operation modes are presented based on the simplified power flow model of the micro-grid including only conversion units, sources and loads as shown in Fig.10. Selection of the operation modes depends on the control objective and energy management scenario and for each scenario, only a limited number of them are selected by EMU. Due to the use of centralized control in this topology, faster system level control with less complexity is possible compared to the micro-grids with the common electrical bus.
On the other hand, a faster and smoother mode transition with minimum effect on the system operation is possible compared to the complex reported methods such as multidrop control for mitigating voltage and frequency variations [34], [35]. To smooth the mode transition process, two techniques are used in this paper. Firstly, a state transition diagram (STD) which clearly shows the mode transition path between any two modes is designed as illustrated in Fig.11. Secondly, a mode transition diagram is designed to check the mode transition conditions, control the steps, adjust the required reference signals and generate the commands as presented in Fig.12. The operation mode M1 is selected as the basic operation mode or bridging mode under the grid-connected condition as this mode is common between all grid-connected modes (grid is always connected to the load in this topology). In the off-grid condition, the battery is the source that is always connected to the load or is in the standby mode. Therefore, M1 is selected as the bridging mode during the mode transition.

Due to a large number of operation modes, using ruledbased energy management methods with a set of casetriggered rules restricts the system flexibility and does not guarantee the optimal operation. Therefore, in this paper, the operation modes are selected according to a $2 \mathrm{D}$ dynamic programming (DP). The DP is a graph-based optimisation technique which defines the best variation path of the system variables to satisfy the objective function through a sequential variation and evaluation process. The advantage 
of the method is that the constraints and the performance index can be linear or non-linear, convex or concave. Although, it needs a large memory space for long processing routes with small steps. The computation time is reduced by using some modification techniques which will be discussed in more details in future publications. In this paper, the transformer and converter efficiencies and the battery charge and discharge losses are included in the optimisation problem. The control objective is to schedule the operation modes of the system to minimize the customer's energy bill. It is assumed that the forecasted profiles of the load demand, PV generation and electricity grid price are available from smart grid control centre and are updated regularly. The physical constraints of the system based on the power balance equations can be written as

$$
\begin{gathered}
P_{F C}+P_{P V}+P_{B T}+P_{G D}-P_{L D}-P_{E L}-P_{L S}=0 \\
P_{L S}=P_{L S, T}+P_{L S, C} \\
P_{L S, C}=P_{L S, B B C}+P_{L S, H B 1}+P_{L S, H B 2}+P_{L S, H B 3}+P_{L S, I N}
\end{gathered}
$$

where $P_{L S}, P_{L S, T}$ and $P_{L S, C}$ are the power losses in the entire micro-grid system, transformer, and the converters respectively. The power loss in the converters includes switching and conduction losses of $\mathrm{H}$-bridge units $\left(P_{L S, H B}\right)$, buck-boost converter $\left(P_{L S, B B}\right)$ and inverter $\left(P_{L S, I N}\right)$. The transformer conduction loss is merged into the converter conduction loss. The power losses are defined according to the linear-piecewise model of the converter efficiency as a function of the input power to the nominal power $\left(\eta_{\text {con }}=f\left(P_{\text {in }} / P_{\text {rated }}\right)\right)$ by using the micro-grid power flow model presented in Fig.10. The battery loss also is defined as a function of charging or discharging power in a similar way $\left(\eta_{B T-C H G}=f\left(P_{B T, C h g}\right), \eta_{B T, D s g}=f\left(P_{B T, D s g}\right)\right)$. Other constraints are related to the battery SOC range, battery charging and discharging power limits, maximum and minimum range of the fuel cell power for operating in the linear (ohmic polarization) area and the power transfer to/from the grid as presented in the below equations.

$$
\begin{gathered}
S O C_{\text {med }}<S O C<S O C_{\text {max }} \Rightarrow \text { Storage application } \\
S O C_{\text {min }}<S O C<S O C_{\text {med }} \Rightarrow \text { Off }- \text { Grid application } \\
P_{B T} \leq P_{B T, \text { max }}, P_{G D} \leq P_{G D \text {,max }} \\
P_{F C \text {,min }}<P_{F C} \leq P_{F C \text {, mx }}, P_{E L} \leq P_{E L, \text { max }}
\end{gathered}
$$

where $S O C_{\text {min }}, S O C_{m e d}$ and $S O C_{\text {max }}$ are the minimum, medium and maximum of the battery SOC levels respectively. $P_{B T, \max }, P_{G D, \max }$ and $P_{E L, \max }$ are the maximum power of the battery, grid and electrolyser. $P_{F C \text {, min }}$ and $P_{F C \text {, max }}$ are the maximum and minimum of the fuel cell power respectively. The objective function of EMU is to find a scheduled variation path for $S O C$ and $S O H$ which results in the minimum cost of the system, $C^{m}(T)$ during the next moving time-frame.

$$
C^{*}(T)=\min C^{m}(T)
$$

Considering that the moving time period $T$ is divided into $n$ sections then

$$
T=\sum_{i=1}^{n} \Delta T_{i}
$$

The cost of the system for the $m$-th path, $C^{m}(T)$ is calculated from

$$
C^{m}(T)=\sum_{i=1}^{n}\left[C^{m}\left(\Delta T_{i}\right)\right]=\sum_{i=1}^{n}\left[C_{R}^{m}\left(\Delta T_{i}\right)+C_{P}^{m}\left(\Delta T_{i}\right)\right]
$$

where $C_{R}^{m}\left(\Delta T_{i}\right)$ is the benefits received from selling energy to the grid and $C_{P}^{m}\left(\Delta T_{i}\right)$ is related to the all operating costs of the system for $i$-th time period $\left(\Delta T_{i}\right)$ of $m$-th path and are defined by

$$
\begin{aligned}
& C_{R}^{m}\left(\Delta T_{i}\right)=\left[P_{G D}\left(\Delta T_{i}\right) * C_{G D_{-} S e l l}\left(\Delta T_{i}\right) * \Delta T_{i}\right] \text { if } P_{G D}\left(\Delta T_{i}\right)\langle 0 \\
& \left.C_{P}^{m}\left(\Delta T_{i}\right)=\left[P_{G D}\left(\Delta T_{i}\right) * C_{G D_{-} B u y}\left(\Delta T_{i}\right) * \Delta T_{i}\right] \text { if } P_{G D}\left(\Delta T_{i}\right)\right\rangle 0
\end{aligned}
$$

where $C_{G D_{-} B u y}$ is the cost of the energy received from the grid and $C_{G D \_S e l l}$, the energy sold to the grid.

Fig.13 illustrates the trajectory of the 2D dynamic programming problem. The problem for each time step ahead $\left(\Delta T_{i}\right)$, starts with the applying a change to the SOC and $\mathrm{SOH}$, presented as $\delta_{\mathrm{SOC}}$ and $\delta_{\mathrm{SOH}}$ respectively, as state variables of the system. $\delta_{S O C}>0$ means that the battery should be in charging mode, $\delta_{S O C}<0$ in discharging mode and $\delta_{S O C}=0$ in standby mode. On the other hand, the electrolyser should be active when $\delta_{\mathrm{SOH}}>0$, fuel cell when $\delta_{S O H}<0$ and both are off when $\delta_{S O H}=0$. The attributed powers $P_{B T}, P_{E L}$ and $P_{F C}$ are calculated accordingly taking into account the constraints in (22) and (25). The PV power generation $\left(P_{P V}\right)$ and load demand $\left(P_{L D}\right)$ are obtained based on the forecasted profiles. The power transfer to/from the grid $\left(P_{G D}\right)$ and the power loss in the system $\left(P_{L S}\right)$ are defined by using (19)-(21) based on the power flow model of the system presented in Fig.10. Finally, the amount of $C^{m}(\Delta T)$ is calculated by using (26) for each time step, $\Delta T_{i}$ and for the entire path $C^{m}(T)$. The final step is to compare the resultant cost of all $m$ paths and select the path with minimum cost as $C^{*}(T)$ using (28)-(30). The searching space and example of two possible paths (R1 and R2) of scheduled variations in $S O C$ and $\mathrm{SOH}$ are illustrated in Fig.13. The resultant change in the $S O C$ and $S O H$ according to the selected path is sent to the mode selection and transition unit (MSTU). The MSTU determines any change in the operation mode by using realtime data of the system and required changes in the $S O C$ and $\mathrm{SOH}$ levels.

More details on the optimisation algorithm, mode selection and transition, and energy management units will be provided in the revisions if required.

\section{Prototyping and Experimental Test}

A prototype of the proposed micro-grid is designed and implemented as presented in Fig.14.(a). Two DSP controllers (C2000/TMS320F28335) are used as device level controller and the system level control including energy management and operation mode control is performed by a Laptop (Asus, FK003QM, CPU: Intel-core i7, $2.6 \mathrm{GHz}, 12 \mathrm{~GB}$ RAM) using a graphical user interface (GUI) in MATLAB. Two sensor and protection boards are designed to receive the measured values of voltage and current through Hall-Effect voltage (LV 25-P) and current (LTSR25-NP) sensors. The MPPT reference signal produced by EMU is sent to the DSP1 to control the duty ratio of switching devices of the PV port. In the proposed system MPPT reference signal is updated every $10 \mathrm{~ms}$ $(f=100 \mathrm{~Hz})$. The single-phase inverter also is implemented using H-bridge units made by SEMIKRON (SK30GH123) with isolated drivers (SKHI20opA). 


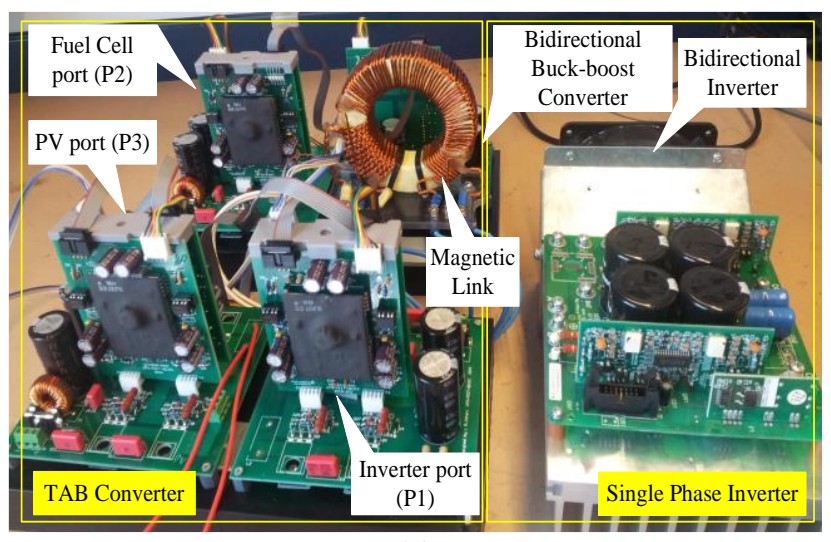

(a)

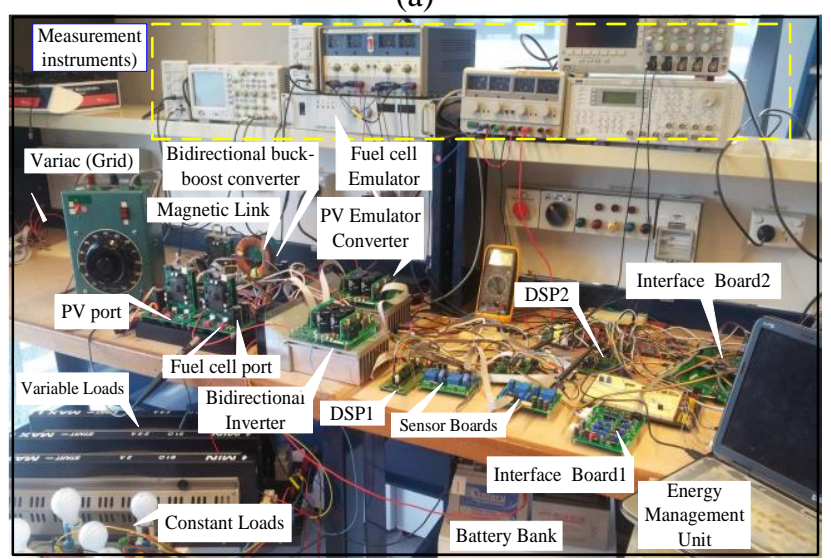

(b)

Fig.14 (a) Prototype of the proposed micro-grid and (b) experimental test set up.

The H-bridge units in the TAB converters are implemented by IGBT switches (IKW40T120) and integrated driver circuit (VLA567-01R) made by Powerex. The experimental test set is presented in Fig.14.(b).

The operation of MSTU in direct and indirect mode transitions is presented in Fig.15. The direct mode transition from M5 to M3 is shown in Fig.15 (a). As can be seen, when the PV power is approached to zero, the fuel cell undertakes to supply the difference and the battery operates as a compensator. In the indirect mode transition from M2 to M3, presented in Fig.15 (b), the mode M1 is used as bridging mode to leave enough time $(14.5 \mathrm{~s})$ for the fuel cell start-up. In Fig.15 (c), the system mode changes from mode 2 where power generated by PV $(\approx 920 \mathrm{~W})$ is consumed by the load $(490 \mathrm{~W})$, transferred to the grid $(-330 \mathrm{~W})$ and lost in the system $(\approx 100 \mathrm{~W})$. As PV generation increases from 0.92 $\mathrm{kW}$ to $1.31 \mathrm{~kW}$, the surplus energy partially supplied to the battery $(160 \mathrm{~W})$ considering the battery SOC level, and the rest are supplied to the grid $(540 \mathrm{~W})$. As can be seen, it takes about $14 \mathrm{~ms}$ for the battery port to be activated for the charging process although, the total transition time is about $75 \mathrm{~ms}$.

The experimental waveforms of the generated ac voltages and currents generated by H-bridge converters of the TAB converter are presented in Fig.16 (a) and (b). As illustrated in Fig.16 (a) where $\left(\varphi_{21}=\pi / 4, \varphi_{31}=\pi / 3\right)$, the currents in the switching devices are positive at falling time and negative at rising time of the voltages which shows the soft switching operation (ZVS) of the converter. Fig.16 (b) shows the waveforms for $\left(\varphi_{21}=\pi / 3, \varphi_{31}=\pi / 6\right)$ where PV port is in light load condition and the soft switching operation is realized.

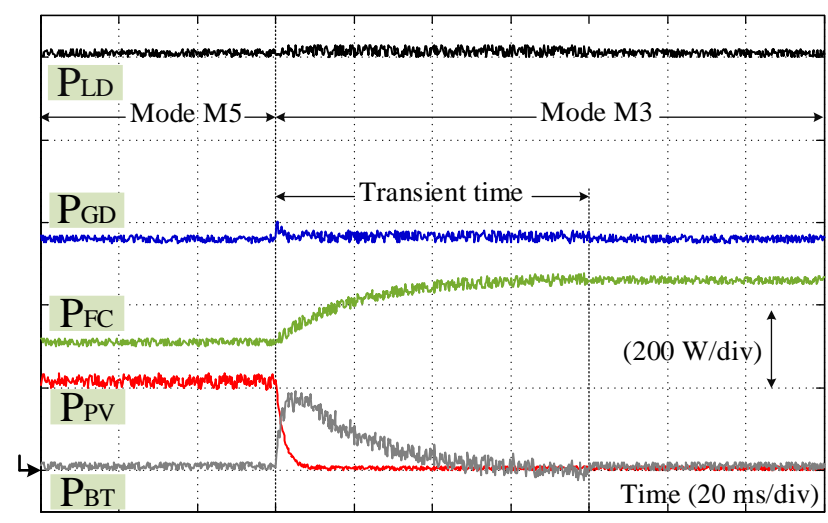

(a)

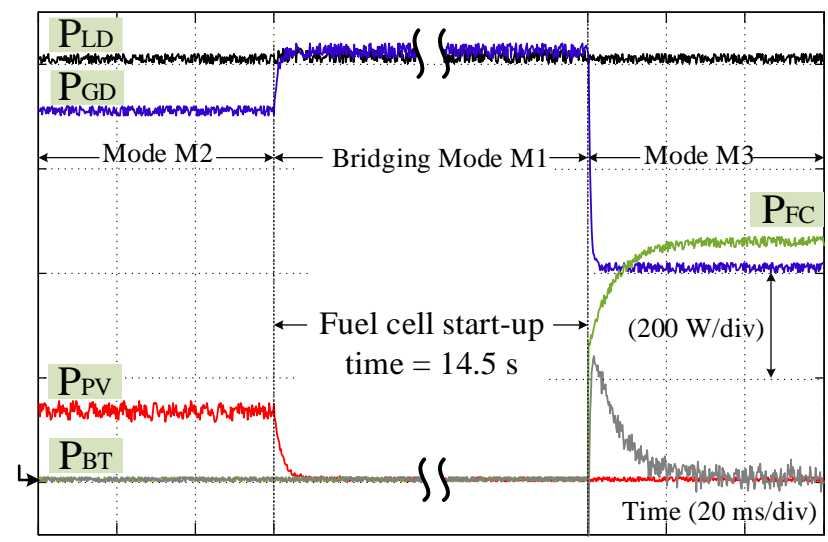

(b)

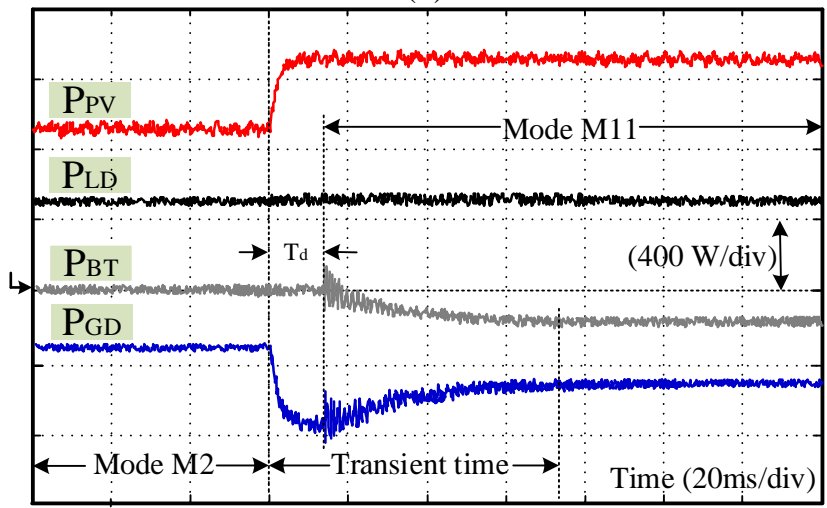

(c)

Fig.15 Operation of MSTU for two cases (a)-direct node transition from $M 5$ to $M 2$, (b) indirect mode transition from $M 2$ to $M 3$ and using $\mathrm{M} 1$ as bridging mode and (c) mode transition from $\mathrm{M} 2$ to M11.

Some experimental tests are conducted to validate the effectiveness of the proposed control techniques. As illustrated in Fig.17, the inverter output current is in sinusoidal form with $\mathrm{THD}=3.27 \%$ which is acceptable range due to the standard (IEEE 1547 and IEC 61727) for residential grid-connected inverters. The effect of using SBVB technique on the improvement of the TAB converter efficiency is presented in Fig.18.(a). As can be seen, the system's efficiency increased by $4 \%$ in $3.5 \mathrm{~kW}$ output power. On the other hand, Fig.18.(b) illustrates the effects of using resonant compensator (RCP) in the PV current control loop on the reduction of low-frequency ripple $(2 \omega)$ in the PV output voltage (by 3\%). It also shows that using compensator block in the inverter control loop reduces the propagated low-frequency ripple by $4.5 \%$ on the high voltage dc bus. 

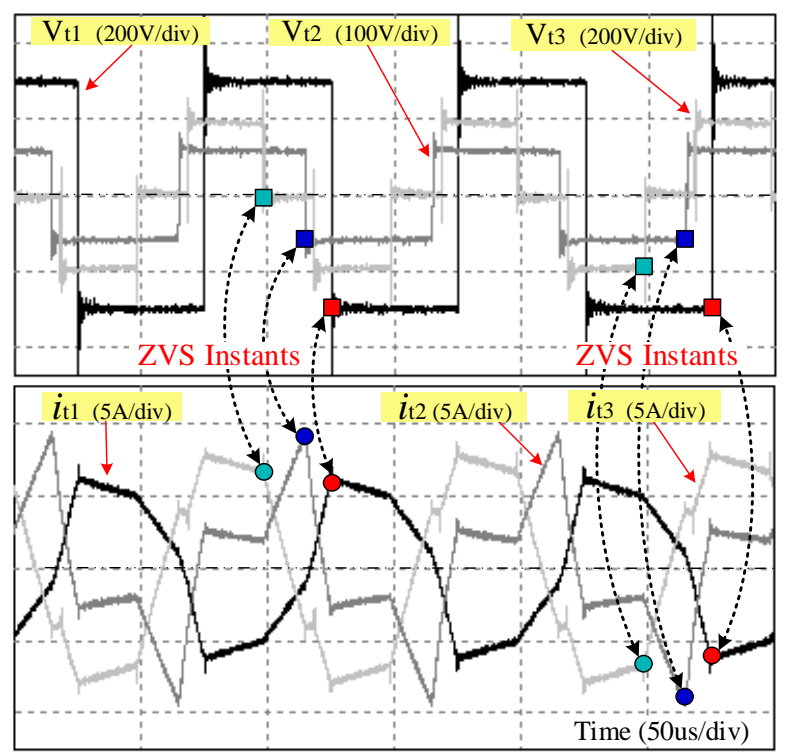

(a)
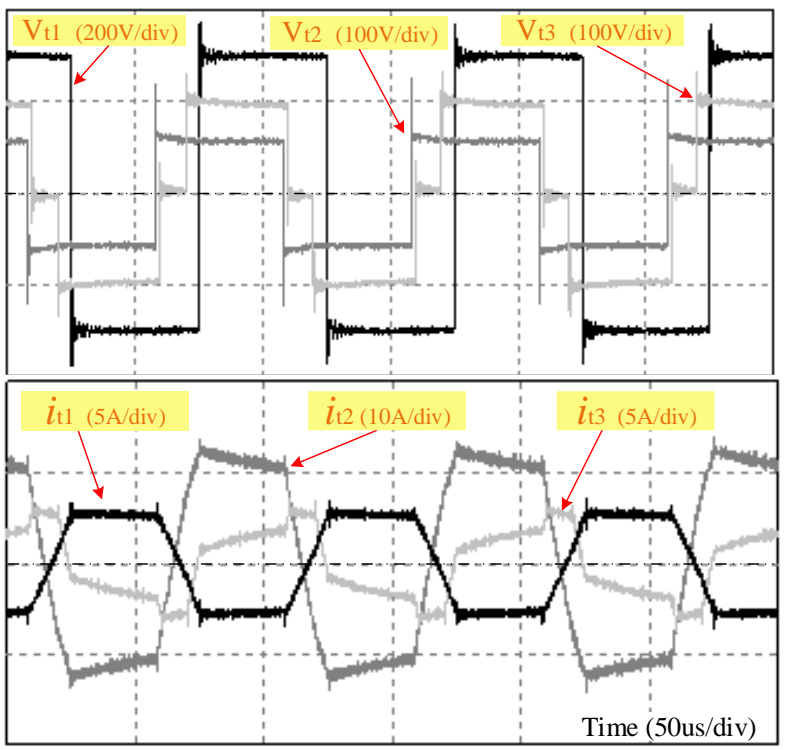

(b)

Fig.16. Experimental waveforms of the TAB converter voltage and currents which shows the soft switching (ZVS) operation, (a) for the case that $(\phi 21=\pi / 4, \phi 31=\pi / 3)$ and, (b) for the case that ( $\phi 21=\pi / 3, \phi 31=\pi / 6)$.

\subsection{Energy Management of the Micro-grid}

To validate the proposed energy management technique, the residential load is implemented by parallel connection of two groups of variable and constant loads as presented in Fig.14.(b). The experimental test is carried out for a time duration of 2 hours to model a 24 hours residential load which starts at 12 AM. According to this, 720 samples with time duration of 10 seconds are used to record the parameters of the proposed micro-grid. The operation of the proposed micro-grid was experimentally tested for a typical sunny day profile. The system is assumed to be in gridconnected mode considering that the amount of power flow to/from the grid, battery, fuel cell and electrolyser are limited to $1 \mathrm{~kW}, 500 \mathrm{~W}, 500 \mathrm{~W}$ and $600 \mathrm{~W}$ respectively. The EMU also records the power flow of the fuel cell, battery, PV, inverter, and load as presented in Fig.19. The discretised forecasted profiles of the PV generation and load demand (except for electrolyser) are also shown to be

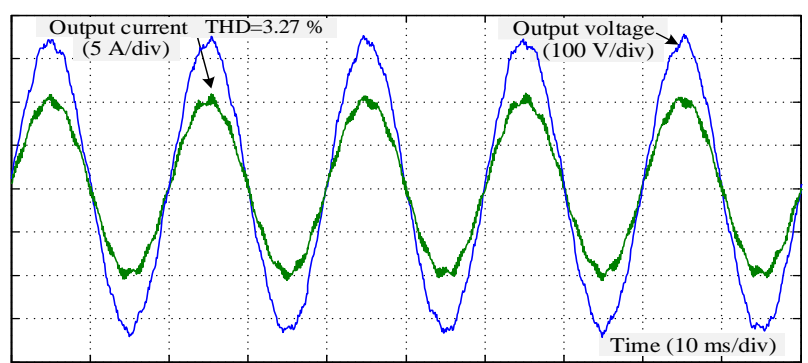

Fig.17. Experimental waveforms of inverter voltage and current.

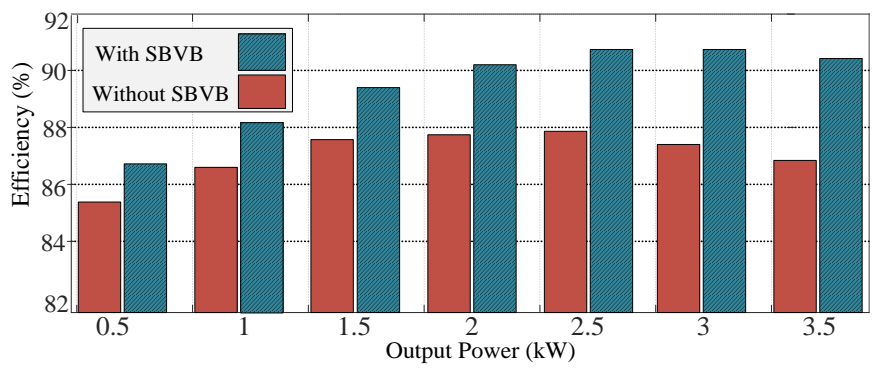

(a)

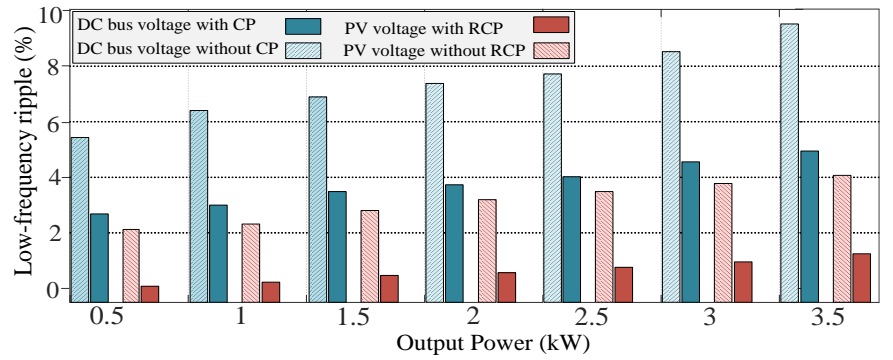

(b)

Fig.18. (a) The micro-grid efficiency with and without using SBVB technique and, (b) voltage ripple on the PV output voltage and high voltage dc bus with and without compensation units in the control loop.

compared with the real-time data. The selected operation modes of the micro-grid are presented at the bottom of the battery power profile and are described in Table.1.

\subsection{Energy Distribution and Cost Analysis}

The power profiles of the PV, fuel cell, battery, load, electrolyser and grid are used to define the total energy supplied or received by each element. As an example, the energy supplied by PV can be determined by

$$
E_{P V_{-} 24 h}=\sum_{k=1}^{720} P_{P V}(k) T_{k}=T_{k} \sum_{k=1}^{720} P_{P V}(k)
$$

where $T_{k}$ is the sampling time and equal to $2 \mathrm{~min}$ for a 24 hour time duration. The energy supplied, absorbed and stored by other elements of the micro-grid can be defined similarly. Fig.20.(a) illustrates the energy analysis of the micro-grid for the profiles presented in Fig.19. It can be seen that almost $48 \%$ of the load energy is provided by PV while fuel cell, battery and the grid supplied nearly $16 \%$, $16 \%$ and $20 \%$ of the total load demand respectively. The energy received from and supplied to the grid are $2.55 \mathrm{~kW}$ and $0.77 \mathrm{~kW}$ respectively. The total energy supplied by the battery is $1.44 \mathrm{kWh}$ which is almost three times of the received energy $(0.47 \mathrm{kWh})$, and therefore, the $S O C$ is reduced to $30 \%$ by the end of the period. To analyse the operation of the micro-grid from an economic point of view, the total cost of the energy supplied, stored or consumed by 
Table.1. Operation modes of the micro-grid

\begin{tabular}{|c|c|}
\hline $\begin{array}{l}\text { Operation modes } \\
\text { in order }\end{array}$ & modes \\
\hline M4 & $\begin{array}{l}\text { As there is no power generated by PV and due to the small } \\
\text { amount of load demand, it can be supplied by either battery } \\
\text { or grid and the battery is selected due to the lower cost. }\end{array}$ \\
\hline M1 & $\begin{array}{l}\text { The cost of grid energy is reduced to less than battery } \\
\text { Therefore, grid is selected as preferred supply and } \\
\text { electrolyser also is turned on. }\end{array}$ \\
\hline M2 & $\begin{array}{l}\text { The PV port is activated as PV panel starts to generate } \\
\text { power. This operation mode continues as long as the PV } \\
\text { power is less than load demand. }\end{array}$ \\
\hline M11 & $\begin{array}{l}\text { The PV generation is more than load demand, the surplus } \\
\text { energy is used to charge the battery due to the long-term } \\
\text { predictions. Due to the limit in the battery charging power, } \\
\text { the additional energy is sent to the main grid. }\end{array}$ \\
\hline M2 & $\begin{array}{l}\text { The battery is fully charged to the SOC }=90 \% \text { and the } \\
\text { surplus energy is sent to the Grid. }\end{array}$ \\
\hline M6 & $\begin{array}{l}\text { The PV generation is less than load demand, the battery is } \\
\text { preferred to supply the Difference due to the lower energy } \\
\text { cost compared to the grid. }\end{array}$ \\
\hline M5 & $\begin{array}{l}\text { The load demand is more than the PV+BT and the fuel cell } \\
\text { is selected due to the lower cost compared to grid. } \\
\text { Therefore fuel cell operates with maximum power and the } \\
\text { difference is covered by battery. }\end{array}$ \\
\hline M12 & $\begin{array}{l}\text { The load demand changes to more than } \mathrm{PV}+\mathrm{FC}+\mathrm{BT} \text {, } \\
\text { therefore, grid supplies the difference. }\end{array}$ \\
\hline $\mathrm{M}$ & $\begin{array}{l}\text { of grid energy decreases to less than battery and } \\
\text { and is selected as preferred source. }\end{array}$ \\
\hline
\end{tabular}

each element is calculated as presented in Fig.20.(b). To calculate the total cost of energy for 24 hours duration, the amount of power and the cost of energy at the sampling time are taken into account. In this paper, the PV energy cost is assumed to be $0.02 \$ / \mathrm{kWh}$, the fuel cell energy cost is 0.3 $\$ / \mathrm{kWh}$, the battery cost during discharge (considering that the battery is often charged by PV or the grid in off-peak hours) is $0.10 \$ / \mathrm{kWh}$ and the grid cost is variable from 0.05 to $0.50 \$ / \mathrm{kWh}$. Looking at the energy cost graph shows that the customer benefits from supplying energy from PV to the grid at peak demand hours when the grid energy cost is 0.5 $\$ / \mathrm{kWh}$ is $0.38 \$ /$ day. This can compensate for the cost of the energy supplied by the other sources. About $60 \%$ (0.39\$/day) of the total energy cost of the load belongs to the fuel cell compared to the other sources. In contrast, in the case that the load only is supplied by the grid with the same cost profile the total energy cost per 24 hours is equal to 2.13 $\$ /$ day while by using renewables this reduces to 0.315 \$/day. This shows about $85 \%$ reduction of energy cost for a typical day which is the customer benefits from using renewable sources. The energy distribution and cost analysis validate the benefits of the proposed micro-grid, control techniques and energy management method.
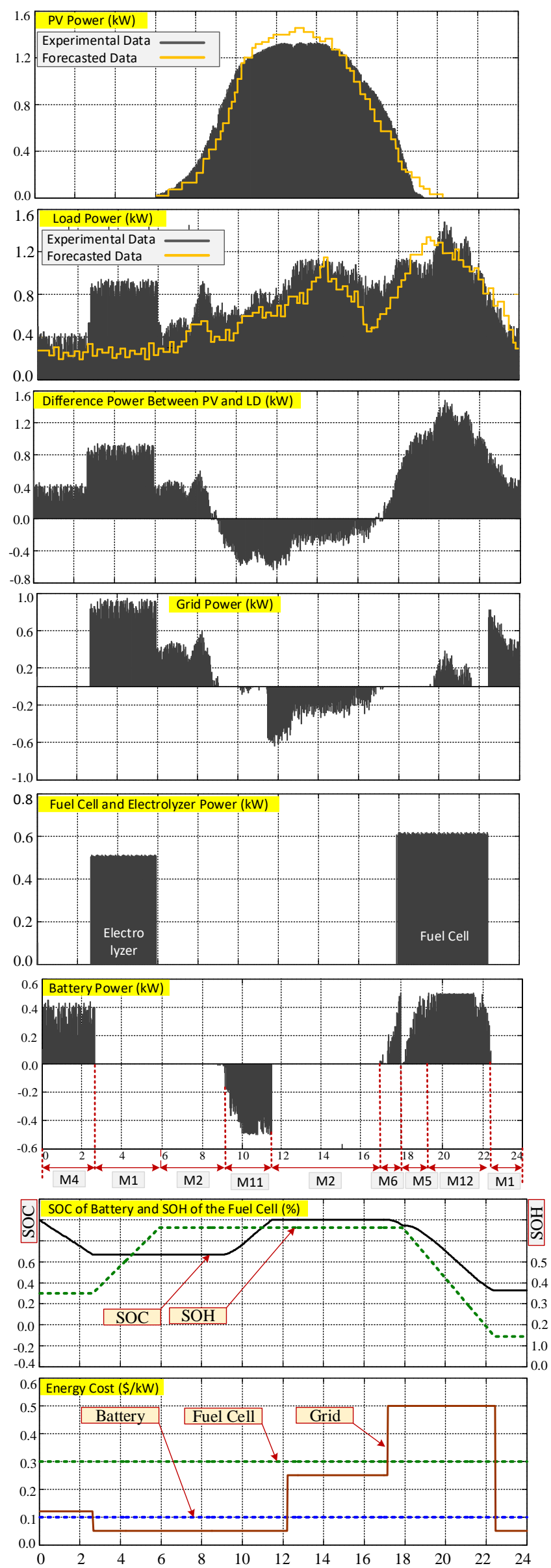

Fig.19. Power profiles of the PV generation, load demand, battery, electrolyser, fuel cell and grid and the battery SOC and fuel cell $\mathrm{SOH}$. 


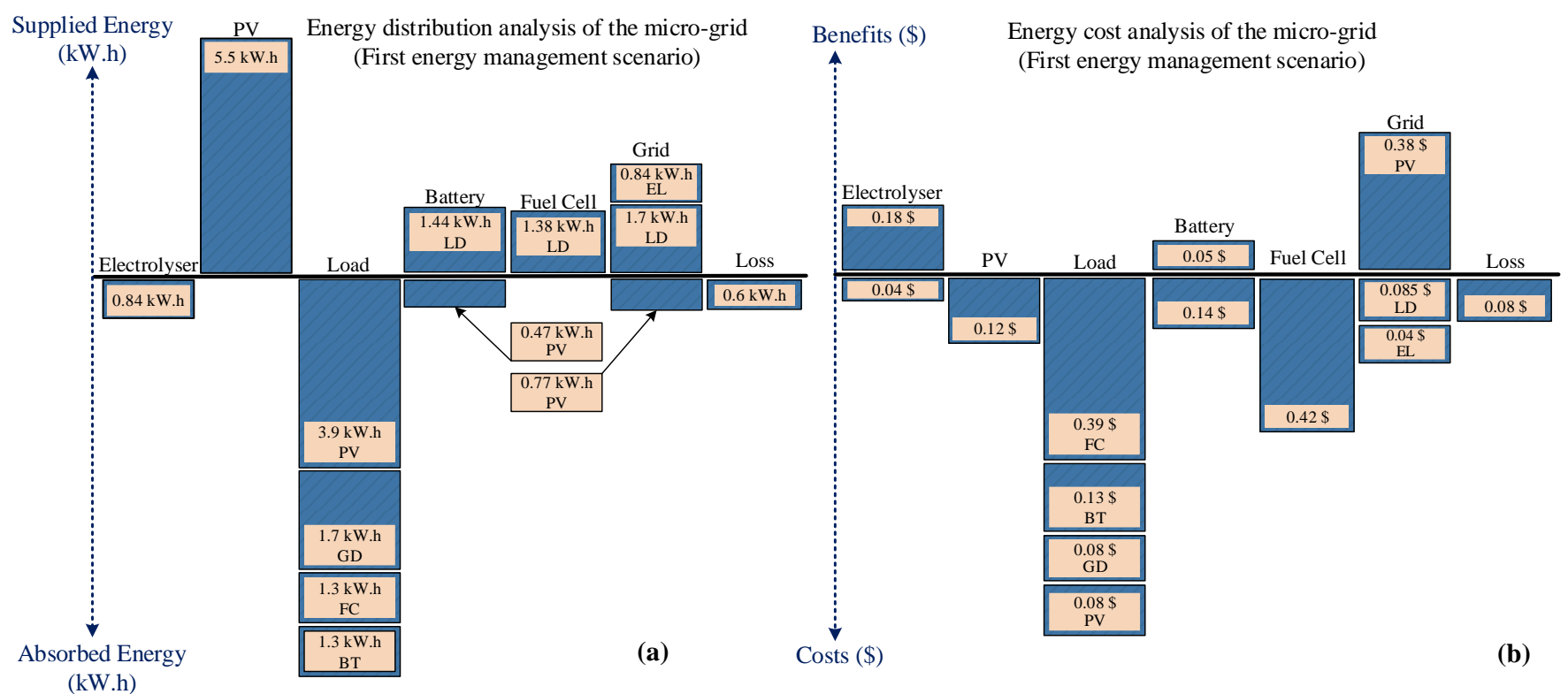

Fig.20. (a) Energy distribution analysis and (b) Energy cost analysis of the proposed micro-grid for a 24 hours time period.

\section{Conclusion}

In this paper, a magnetically coupled micro-grid topology was presented and steady state operation, controller design and energy management technique were studied. To improve the MPPT performance, the SBVB technique is used which reduced the current ripple of the PV port by $5 \%$ and increased the entire micro-grid efficiency by $4 \%$. The inclusion of a resonant element as a compensator in the inverter control loop reduced the propagated low-frequency ripple on the HVDC bus by $4 \%$. A predictive $2 \mathrm{D}$ dynamic programming method is used to manage the energy distribution in the micro-grid optimally. The energy losses in the micro-grid elements such as converters, transformer and battery were taken into account. The effectiveness of the control techniques and energy management method was validated through experimental tests on a developed prototype.

\section{Appendix-(A)}

Table.2. Parameters of the micro-grid

\begin{tabular}{lll}
\hline \multicolumn{1}{c}{ Description } & \multicolumn{1}{c}{ Symbol } & \multicolumn{1}{c}{ Value } \\
\hline dc voltage of the converter ports & $\mathrm{V}_{\mathrm{b} 1}, \mathrm{~V}_{\mathrm{b} 2}, \mathrm{~V}_{\mathrm{b} 3}$ & $320 \mathrm{~V}, 60 \mathrm{~V}, 110 \mathrm{~V}$ \\
Transformer turns ratio & $N_{1}, N_{2}, N_{3}$ & $52,10,17$ \\
Leakage inductances & $L_{l 1}, L_{l 2}, L_{l 3}$ & $80 \mu \mathrm{H}, 5 \mu \mathrm{H}, 18 \mu \mathrm{H}$ \\
Switching frequency & $f_{s}$ & $10 \mathrm{kHz}$ \\
DC bus capacitors & $C_{2}, C_{3} / C_{5}$ & $800 / 1200 \mu \mathrm{f}$ \\
PV, battery and Fuel cell voltage & $V_{P V}, V_{B T}, V_{F C}$ & $0-30 \mathrm{~V}, 24 \mathrm{~V}, 60 \mathrm{~V}$ \\
Magnetic core material & $\mathrm{Amorphous}$ & $2605 \mathrm{SA} 1$ \\
Fuel cell , PV power & $P_{F C}, P_{P V}$ & $2 \mathrm{kVA}, 1.5 \mathrm{kVA}$ \\
Battery type & $\mathrm{Lead}-\mathrm{Acid}$ & $2 * 12 \mathrm{~V} / 100 \mathrm{~A} . \mathrm{h}$ \\
AC load power & $\mathrm{P}_{\mathrm{LD}}$ & $4 \mathrm{~kW}$ \\
Buck-boost and boost inductors & $\mathrm{L}_{1}, \mathrm{~L}_{2} / \mathrm{L} \mathrm{L}_{3}$ & $100 \mu \mathrm{H}, 80 \mu \mathrm{H}$ \\
Output low pass filter parameters & $L_{O}, C_{O}$ & $4 \mathrm{mH}, 5 \mu \mathrm{f} / 440 \mathrm{~V}$ ac \\
PV and Battery output capacitor & $C_{1}, C_{4}$ & $220 \mu \mathrm{f}, 420 \mu \mathrm{f}$ \\
Inductor DC resistance & $r_{L 1}, r_{L 2} / r_{L 3}$ & $0.12 \Omega, 0.05 \Omega$ \\
\hline
\end{tabular}

Appendix-(B)

$$
\begin{aligned}
& L_{1} \frac{d i_{L_{1}}}{d t}=-i_{L_{1}} r_{L_{1}}+v_{b 2}-v_{C_{1}} \\
& \left\{C_{2} \frac{d v_{b 2}}{d t}=-\frac{v_{b 2}-V_{F C}}{R_{F C}}-i_{L_{1}}-i_{O}\right. \\
& C_{1} \frac{d v_{C_{1}}}{d t}=-\frac{v_{C_{1}}-V_{B T}}{R_{B T}}+i_{L_{1}} \\
& \left.G_{i-B B}(s)=\frac{\hat{i}_{1}(s)}{d(s)}=\frac{R_{B T}\left(s+\frac{1}{C_{1} R_{B T}}\right)\left[\left(s+\frac{1}{C_{2} R_{F C}}\right) \frac{\bar{v}_{b 2}}{L_{1}}-\frac{D_{4} \bar{i}_{L_{1}}}{L_{1} C_{2}}\right]}{\left[\left(s+\frac{1}{C_{2} R_{F C}}\right)\left(s+\frac{1}{C_{1} R_{B T}}\right)\left(s+\frac{r_{L_{1}}}{L_{1}}\right)+\frac{\left(s+\frac{1}{C_{2} R_{F C}}\right)}{L_{1} C_{1}}+\frac{D_{4}^{2}\left(s+\frac{1}{C_{1} R_{B T}}\right)}{L_{1} C_{2}}\right]}\right] \\
& \text { Interleaved boost converter } \\
& \left\{\begin{array}{cll}
L \frac{d i_{L}}{d t}=V_{p v}-i_{L} r_{L} & 0<t<D_{3}^{\prime} T & G_{i-V}=\frac{I_{L}(s)}{v_{b 3}(s)}=\frac{-D_{3}^{\prime}}{s L+r_{L}} \\
L \frac{d i_{L}}{d t}=V_{p v}-i_{L} r_{L}-v_{b 3} & D_{3}^{\prime} T<t<T & G_{i-d}=\frac{I_{L}(s)}{d_{3}^{\prime}(s)}=-\frac{V_{b 3}}{s L+r_{L}}
\end{array}\right. \\
& C_{4} \frac{d v_{P V}}{d t}+i_{L}+\frac{v_{P V}}{R_{m p p}}-I_{m p p}=0 \quad G_{v-P V}(s)=\frac{v_{P V}(s)}{i_{L}(s)}=\frac{-R_{m p p}}{1+s C_{4} R_{m p p}} \\
& G_{v-B B}(s)=\frac{\hat{v}_{C_{1}}(s)}{\hat{d}(s)}=\frac{\frac{1}{C_{1}}}{s+\frac{1}{C_{1} R_{B T}}} \cdot \frac{\hat{i}_{L_{1}}(s)}{\hat{d}(s)}
\end{aligned}
$$

\section{References}

[1] IPCC Fourth Assessment Report: Climate Change 2007, https://www.ipcc.ch/publications_and_data/ar4/wg1/en/tsst s-3-1-1.html

[2] Clean-Energy-Australia-Report-2014, www.cleanenergycouncil.org.au/reports

[3] H. Tao, A. Kotsopoulos, J. L. Duarte, and M. A. M. Hendrix, "Family of multiport bidirectional DC-DC converters," IEE proceedings of Electric Power Applications, Vol.153, Issue: 3, pp.451-458, 2006

[4] http://www.cleanenergyregulator.gov.au/RET/Schemeparticipants-and-industry /Agents-andinstallers/Installation-requirements-for-small-scale-systems

[5] http://www.yourhome.gov.au/energy/smart-metersdisplays-and-appliances

[6] http://new.abb.com/power-converters-inverters/solar and http://www.sma-

australia.com.au/products/solarinverters.html

[7] Mian Hu, Jiang-Wen Xiao, Shi-Chang Cui, Yan-Wu Wang, "Distributed real-time demand response for energy 
management scheduling in smart grid," International Journal of Electrical Power \& Energy Systems, Vol.99,pp. 233-245,2018.

[8] Yantai Huang, Hongjun Tian, Lei Wang, "Demand response for home energy management system," International Journal of Electrical Power \& Energy Systems, Vol.73, pp. 448-455, 2015.

[9] Y. Riffonneau, S. Bacha, F. Barruel and S. Ploix, "Optimal Power Flow Management for Grid Connected PV Systems With Batteries," IEEE Trans. Sustainable Energy, vol. 2, no. 3, pp. 309-320, July 2011.

[10] L. Zhang and Y. Li, "Optimal Energy Management of Wind-Battery Hybrid Power System With Two-Scale Dynamic Programming," IEEE Trans.Sustainable Energy, vol. 4, no. 3, pp. 765-773, July 2013.

[11] H. Kanchev, D. Lu, F. Colas, V. Lazarov and B. Francois, "Energy Management and Operational Planning of a Microgrid With a PV-Based Active Generator for Smart Grid Applications," IEEE Tran. Ind.Electron., vol. 58, no. 10, pp. 4583-4592, Oct. 2011.

[12] C. Wang and M. H. Nehrir, "Power Management of a Stand-Alone Wind/Photovoltaic/Fuel Cell Energy System," IEEE Trans. Energy Conversion, vol. 23, no. 3, pp. 957-967, Sept. 2008.

[13] D. Arcos-Aviles, J. Pascual, L. Marroyo, P. Sanchis and F. Guinjoan, "Fuzzy Logic-Based Energy Management System Design for Residential Grid-Connected Microgrids," IEEE Trans.Smart Grid, vol. 9, no. 2, pp. 530543, March 2018.

[14] Y. K. Chen, Y. C. Wu, C. C. Song and Y. S. Chen, "Design and Implementation of Energy Management System With Fuzzy Control for DC Microgrid Systems," IEEE Trans. Power Electron., vol. 28, no. 4, pp. 1563-1570, April 2013.

[15] Z. Wu, X. P. Zhang, J. Brandt, S. Y. Zhou and J. N. LI, "Three Control Approaches for Optimized Energy Flow With Home Energy Management System," IEEE Power and Energy Technology Systems Journal, vol. 2, no. 1, pp. 21-31, March 2015.

[16] L. Igualada, C. Corchero, M. Cruz-Zambrano and F. J. Heredia," Optimal Energy Management for a Residential Microgrid Including a Vehicle-to-Grid System,'IEEE Trans. Smart Grid, vol. 5, no. 4, pp. 2163-2172, July 2014.

[17] T. R. Oliveira; W. W. A. G. Silva; P. F. Donoso-Garcia, “Distributed Secondary Level Control for Energy Storage Management in DC Microgrids," IEEE Trans. Smart Grid, vol.PP, no.99, pp.1-11

[18] H. Kakigano, Y. Miura and T. Ise,"Low-Voltage BipolarType DC Microgrid for Super High Quality Distribution,"IEEE Trans. Power Electron, vol. 25, no. 12, pp. 3066-3075, Dec. 2010.

[19] H.Tao, A. Kotsopoulos, J. L. Duarte and M. A. M. Hendrix, "Transformer-Coupled Multiport ZVS Bidirectional DCDC Converter With Wide Input Range," IEEE Trans. Power Electron., vol. 23, no. 2, pp. 771-781, March 2008

[20] M. Jafari, Z. Malekjamshidi, G. Lei, T. Wang, G. Platt and J. Zhu, "Design and Implementation of an Amorphous High-Frequency Transformer Coupling Multiple Converters in a Smart Microgrid,"IEEE Trans. Ind. Electron., vol. 64, no. 2, pp. 1028-1037, Feb. 2017.

[21] C. Zhao, S.D.Round, and J.W.Kolar, "An isolated threeport bidirectional DC-DC converter with decoupled power flow management," IEEE Trans. Power Electron., vol. 23, no. 5, pp. 2443-2453, Sep. 2008.

[22] H. Tao, J. L. Duarte, M. A. M. Hendrix, "Three-port triplehalf bridge bidirectional converter with zero voltage switching," IEEE Trans. Power Electron., vol. 23, no.2, pp 782-792, March 2008.
[23] G. R. Chandra Mouli; J. Schijffelen; P. Bauer; M. Zeman, "Design and Comparison of a $10 \mathrm{~kW}$ Interleaved Boost Converter for PV Application Using Si and SiC Devices," IEEE Journal of Emerging and Selected Topics in Power Electronics, vol. PP, no.99, pp.1-1,2016.

[24] Y. Shi, R. Li, Y. Xue and H. Li, "High-Frequency-LinkBased Grid-Tied PV System With Small DC-Link Capacitor and Low-Frequency Ripple-Free Maximum Power Point Tracking," IEEE Trans. Power Electron., vol. 31, no. 1, pp. 328-339, Jan. 2016.

[25] H. Wu, P. Xu, H. Hu, Z. Zhou and Y. Xing, "Multiport Converters Based on Integration of Full-Bridge and Bidirectional DC-DC Topologies for Renewable Generation Systems," IEEE Trans. Ind. Electron., vol. 61, no. 2, pp. 856-869, Feb. 2014.

[26] Tao, H.(2008).Phd thesis, "Integration of sustainable energy sources through power electronic converters in small distributed electricity generation systems" Eindhoven Technische Universiteit Eindhoven .

[27] Zhang, Junhong.(2008).Phd thesis, "Bidirectional dc-dc power converter design optimization, modeling and control " Blacksburg, Virginia, Virginia Polytechnic Institute.

[28] P.Jose and N.Mohan. "A novel bidirectional dc-dc converter with ZVS and interleaving for dual voltage systems in automobiles," in Proc. IEEE IAS, Pittsburg, Pennsylvania, Volume 2. Oct.2002, pp. 1311-1314.

[29] O. Hegazy, J. V. Mierlo and P. Lataire, "Analysis, Modeling, and Implementation of a Multidevice Interleaved DC/DC Converter for Fuel Cell Hybrid Electric Vehicles," IEEE Trans. Power Electron., vol. 27, no. 11, pp. 4445-4458, Nov. 2012.

[30] A. Karimi, D. Garcia and R. Longchamp, "PID controller tuning using Bode's integrals,"IEEE Trans. Control Systems Technology, vol. 11, no. 6, pp. 812-821, Nov. 2003

[31] F. Liu, S. Duan, F. Liu, B. Liu and Y. Kang, "A Variable Step Size INC MPPT Method for PV Systems," IEEE Trans. Ind. Electron., vol. 55, no. 7, pp. 2622-2628, July 2008.

[32] B. Yang, W. Li, Y. Zhao and X. He, "Design and Analysis of a Grid-Connected Photovoltaic Power System," IEEE Trans. Power Electron., vol. 25, no. 4, pp. 992-1000, April 2010.

[33] M. P. Kazmierkowski and L. Malesani, "Current control techniques for three-phase Voltage-Source PWM Converters: A survey," IEEE Trans. Ind. Electron., vol. 45, no. 5, pp. 691-703, Oct. 1998

[34] Y. Sun, X. Hou, J. Yang, H. Han, M. Su and J. M. Guerrero, "New Perspectives on Droop Control in AC Microgrid,'IEEE Trans. Ind. Electron., vol. 64, no. 7, pp. 5741-5745, July 2017.

[35] O. Cornea, G. D. Andreescu, N. Muntean and D. Hulea, "Bidirectional Power Flow Control in a DC Microgrid Through a Switched-Capacitor Cell Hybrid DC-DC Converter," IEEE Trans. Ind. Electron., vol. 64, no. 4, pp. 3012-3022, April 2017. 